\title{
Giant Vascular Eccrine Spiradenoma with Unusual Clinical Presentation: A Case Report
}

\author{
Kavita Krishnan, Antony Thomas \\ Prime Medical Center, Dubai, UAE \\ Email: drkavita@premierdiagnostics.ae, drantony@premierdiagnostics.ae
}

Received 26 February 2014; revised 26 March 2014; accepted 4 April 2014

Copyright (C) 2014 by authors and Scientific Research Publishing Inc.

This work is licensed under the Creative Commons Attribution International License (CC BY).

http://creativecommons.org/licenses/by/4.0/

(c) (i) Open Access

\begin{abstract}
Giant Vascular Eccrine Spiradenoma (GVES) is a rare variant of Eccrine Spiradenoma (ES), a tumor that develops from the sweat gland. It differs from Eccrine Spiradenoma in its larger size and vascularity as well as propensity for bleeding and ulceration, which may cause a clinical misdiagnosis of vascular lesion or malignant tumor. All previously reported cases in English literature have been in older adults and the elderly, age range being from 49 to 84 years. Here a rare case of GVES in a young male presenting as a cutaneous chest wall lesion with bleeding, which was initially diagnosed as a vascular lesion clinically as well as on histopathology is reported.
\end{abstract}

\section{Keywords}

\section{Vascular Adnexal Spiradenoma Bleeding}

\section{Introduction}

Eccrine Spiradenomas are sharply delimited, lobular lesions that can occur almost anywhere in the body and can be extremely painful. They originate from the lower portion of eccrine duct and are microscopically very cellular. They can also be confused clinically and microscopically with vascular tumors because of their high degree of vascularity [1]. Ultrastructural and immunohistochemical studies have shown that these tumors contain a mixture of epithelial (secretory) and myoepithelial cells [2]. GVES is a variant of Eccrine Spiradenoma. It is very rare, distinguished by its large size clinically $>2 \mathrm{~cm}$ and high vascularity on histopathology [3] [4]. Clinical features of previously reported cases in English Literature are summarized as follows:

Here we report a case of GVES in a young adult male aged 31 years, presenting as a circumscribed chest wall 
mass, clinically diagnosed as a vascular lesion in view of its easy tendency to bleed.

\section{Case Report}

A 31-year-old Indian male had a solitary mass lesion on the chest wall, which had begun as a small nodule 1 year ago and gradually increased in size, with surface excoriation of skin and bleeding at times. Physical examination showed a $2.5 \mathrm{~cm}$ in size, grey brown, circumscribed firm nodule on the chest wall left side. There were no abnormal findings other than the cutaneous lesion. An excision biopsy was performed. On gross examination globular, well circumscribed skin covered lesion measuring $2.5 \times 2.5 \times 1 \mathrm{~cm}$, grey brown in color with areas of surface ulceration. Specimen was bisected and fully processed for microscopy. Epidermis showed areas of surface ulceration. Reticular dermis showed a nodular, vascular tumor composed of basophilic lobules containing 2 cell types: one was characterized by small dark nuclei with minimal cytoplasm, the other had larger pale nucleus. Scattered hyalinized stromal inclusions were present throughout the tumor lobules as well as scattered lymphocytes. The perilobular stroma showed marked vascular dilatation (Figure 1).

Differential diagnosis on microscopy was benign vascular lesion-glomangioma, hemangioma with endovascular growth pattern and epithelioid hemangioma. Possibility of a vascular Eccrine Spiradenoma was considered additionally on the basis of certain histologic features. Immunohistochemistry was performed with SMA and Pan CK. SMA was only focally positive in the myoepithelial component (Figure 2). Pan CK was highly positive among the tumor cells (Figure 3). Based on the lesion size, microscopic and immunohistochemical features, final diagnosis of Giant Vascular Eccrine Spiradenoma was made.

\section{Discussion}

GVES, first described by Cotton and Slater in 1986, is a rare variant of ES which is larger in size and has high vascularity. Bleeding and ulceration are common clinical features of this lesion, hence it may be erroneously diagnosed as a vascular or malignant tumor. In English literature, there are only 8 previously reported cases of GVES, which are summarized in Table 1. All the previous lesions have been reported in older adults or elderly individuals. The present case, even though similar to most previous ones in its clinical manifestation of slow growth, ulceration, bleeding and initially being diagnosed as a vascular lesion, differs in that it is diagnosed in a young adult, hence the occurrence of this lesion in younger individuals is to be considered in the clinical context.

Microscopic morphology of GVES is similar to Eccrine Spiradenoma. The lesion comprises of several lobules,

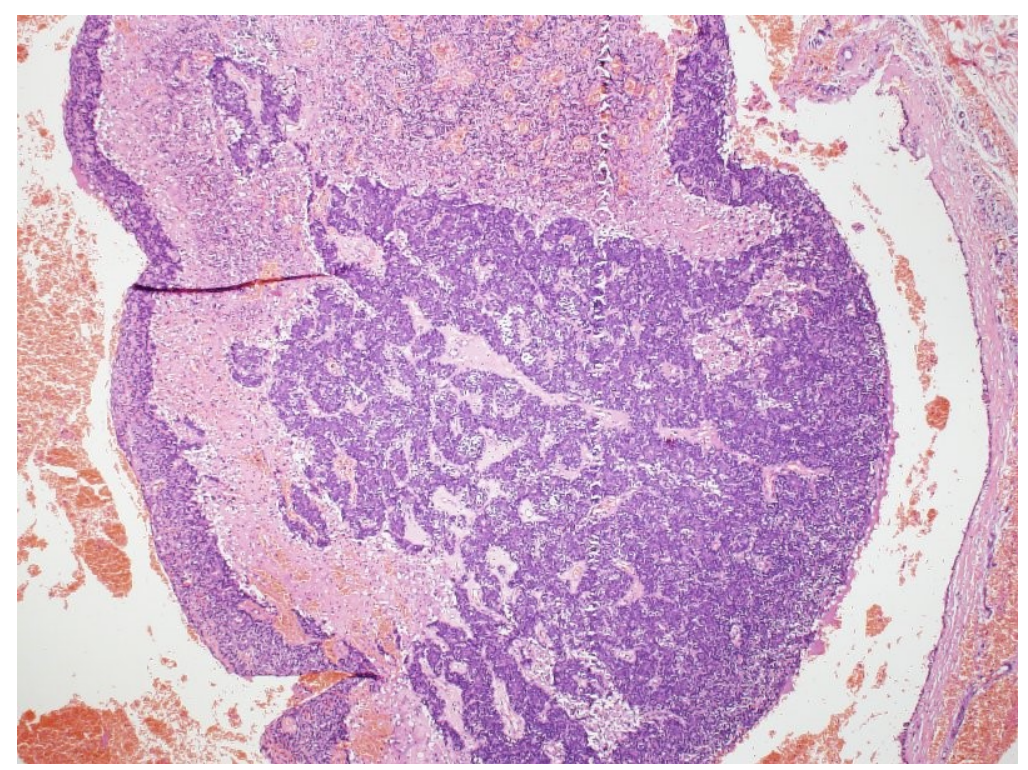

Figure 1. Nodular vascular dermal tumor showing marked dilatation of perilobular stroma. 


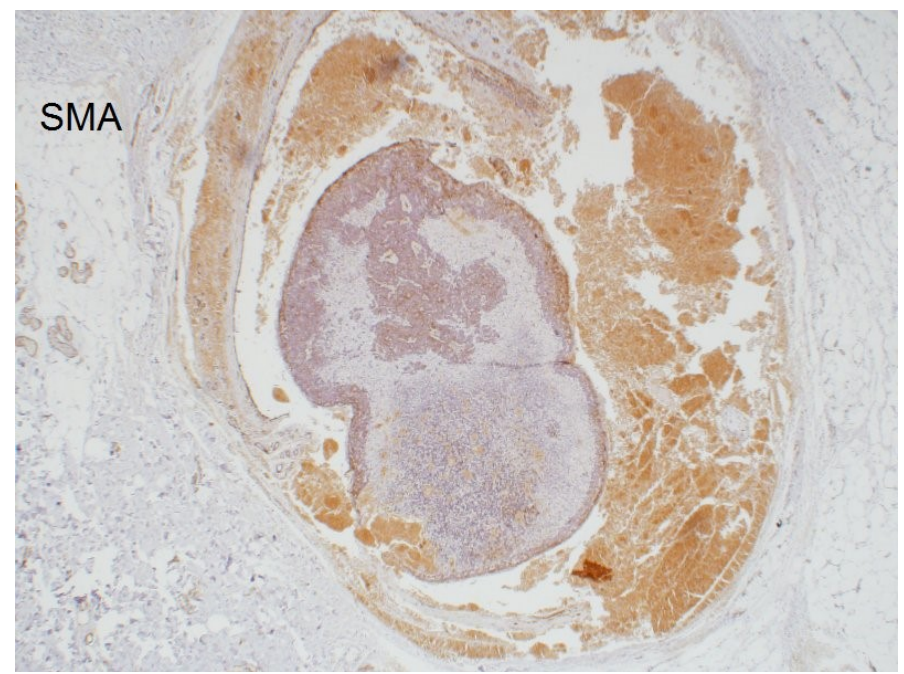

Figure 2. SMA focally positive among myoepithelial cells.

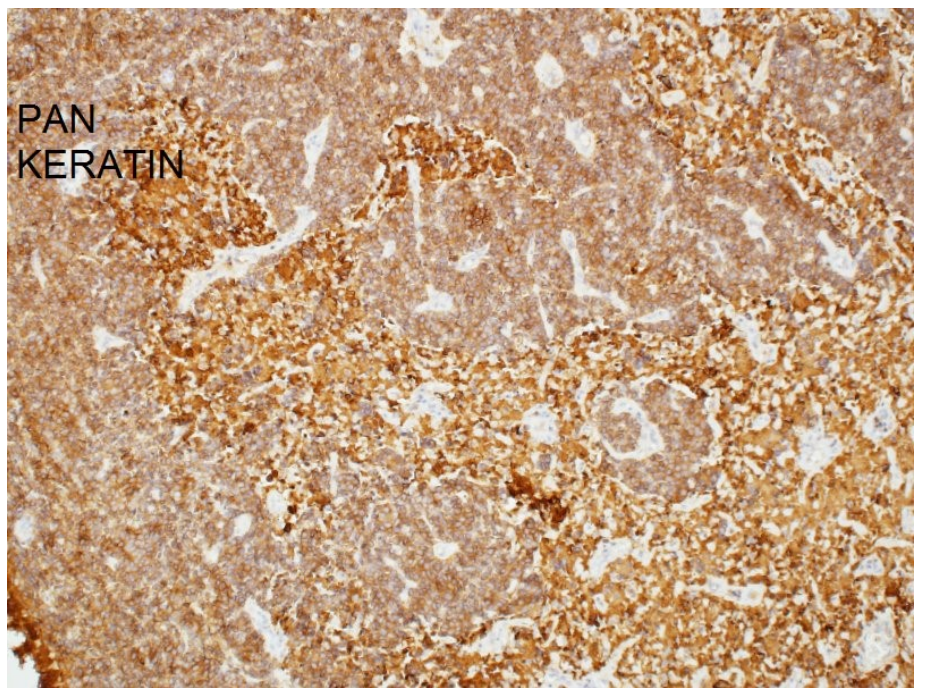

Figure 3. Pan CK highly positive among tumor cells.

Table 1. Summary of previously reported cases in English literature.

\begin{tabular}{|c|c|c|c|c|c|}
\hline Reference & Year & Age/Gender & Size $(\mathrm{cm})$ & Location & Clinical Diagnosis \\
\hline Cotton et al. [1] & 1986 & $74 / \mathrm{M}$ & 5 & Abdomen & Angiosarcoma/Melanoma \\
\hline Cotton et al. [1] & 1986 & $84 / F$ & 2 & posterior scalp & Sebaceous cyst \\
\hline Hey et al. [5] & 1988 & $63 / F$ & $3.5 \times 1.5$ & Thigh & Venous thrombosis \\
\hline Senol et al. [6] & 1988 & $60 / \mathrm{M}$ & 3 to 4 & Costochondral line & Angiomatous lesion \\
\hline Ko et al. [7] & 2006 & $56 / \mathrm{F}$ & 2 & Lower back & Angiolipoma/Neuroma \\
\hline Yamakoshi et al. [8] & 2009 & 76/M & $5 \times 3.4$ & Right shoulder & Not mentioned \\
\hline Kim et al. [9] & 2011 & $49 / \mathrm{F}$ & $2.5 \times 2.5$ & Right upper arm & Vascular tumor \\
\hline Hatano et al. [10] & 2013 & $52 / \mathrm{F}$ & $3.5 \times 2.2$ & Left upper arm & Calcifying epithelioma \\
\hline Present Case & 2013 & $31 / \mathrm{M}$ & $2.5 \times 2.5$ & Chest wall & Hemangioma \\
\hline
\end{tabular}


nests and anastomosing cords of cells located in the dermis without connections to the epidermis. The cells are of two types as described previously. One with small dark nuclei located at the Periphery and the other with small pale nuclei in the centre of the lobules.

Characteristic histopathologic features of GVES are large number of wide vessels filled with red blood cells or lymph fluid in the stroma and an extensive hemorrhagic appearance.

Immunohistochemical profile of the lesion is luminal cells showing positivity for epithelial markers such as Pan CK/EMA and myoepithelial differentiation highlighted by SMA, also could be delineated with p63.

We have described this case in view of its rarity, unusual presentation in a young individual unlike previous reports and its clinical and pathological significance of being easily mistaken for a vascular or malignant tumor because of its hemorrhagic and/or ulcerative tendency.

\section{References}

[1] Cotton, D.W.K., Slater, D.N., Rooney, N., Goepel, J.R. and Mills, P.M. (1986) Giant Vascular Eccrine Spiradenomas: A Report of Two Cases with Histology, Immunohistology and Electron Microscopy. Histopathology, 10, 1093-1099. http://dx.doi.org/10.1111/j.1365-2559.1986.tb02546.x

[2] Al-Nafussi, A., Blessing, K. and Rahilly, M. (1991) Non-Epithelial Cellular Components in Eccrine Spiradenoma: A histological and Immunohistochemical Study of 20 Cases. Histopathology, 18, 155-160. http://dx.doi.org/10.1111/j.1365-2559.1991.tb01458.x

[3] Eckert, F., Betke, M., Schmoeckel, C., Neuweiler, J. and Schmid, U. (1992) Myoepithelial Differentiation in Benign Sweat Gland Tumors. Demonstrated by a Monoclonal Antibody to Alpha-Smooth Muscle Actin. Journal of Cutaneous Pathology, 19, 294-301. http://dx.doi.org/10.1111/j.1600-0560.1992.tb01365.x

[4] Jitsukawa, K., Sucki, H., Sato, S. and Anzai, T. (1987) Eccrine Spiradenoma: An Electron Microscopic Study. American Journal of Dermatopathology, 9, 99-108 http://dx.doi.org/10.1097/00000372-198704000-00003

[5] Hey, A., Grouls, V. and Röckelein, G. (1988) Vascular Eccrine Giant Spiradenoma-A Case Report with Histology and Immunohistology of a Rare Variant of Benign Sweat Gland Tumors. Zeitschrift für Hautkrankheiten, 63, 444-447.

[6] Senol, M., Ozcan, A., Sasmaz, S., Ozen, S. and Ciralik, H. (1998) Giant Vascular Eccrine Spiradenoma. International Journal of Dermatology, 37, 221-223. http://dx.doi.org/10.1046/j.1365-4362.1998.00461.x

[7] Ko, J.Y., Lee, C.W., Moon, S.H., Song, K.W. and Park, C.K. (2006) Giant Vascular Eccrine Spiradenoma: Report of a Case with Immunohistochemical Study. Journal of Korean Medical Science, 21, 172-176.

http://dx.doi.org/10.3346/jkms.2006.21.1.172

[8] Yamakoshi, T., Makino, T., Watanabe, H., Furuichi, M., Matsui, K. and Shimizu, T. (2009) A Case of Giant Vascular Eccrine Spiradenoma with Unusual Clinical Features. Clinical and Experimental Dermatology, 34, e250-e251. http://dx.doi.org/10.1111/j.1365-2230.2008.03122.x

[9] Kim, M.H., Cho, E., Lee, J.D. and Cho, S.H. (2011) Giant Vascular Eccrine Spiradenoma. Annals of Dermatology, 23, 197-200.

[10] Hatano, A., Kobayashi, T., Fukuzumi, S., Shirakashi, Y., Nishimura, C., Gomi, H., Saiga, H. and Hayakawa, K. (2013) Giant Vascular Eccrine Spiradenoma Mimicking Calcifying Epithelioma. The Journal of Dermatology, 40, 853-854. http://dx.doi.org/10.1111/1346-8138.12254 